Case Report

\title{
Dupuytren's Contracture Cosegregation with Limb-Girdle Muscle Dystrophy
}

\author{
Baiba Lace, ${ }^{1}$ Inna Inashkina, ${ }^{1}$ Ieva Micule, ${ }^{2}$ Inta Vasiljeva, ${ }^{1}$ Maruta Solvita Naudina, \\ Jurgis Strautmanis, ${ }^{4}$ Janis Stavusis, ${ }^{1}$ and Eriks Jankevics ${ }^{1}$ \\ ${ }^{1}$ Latvian Biomedical Research and Study Centre, Ratsupites Street 1, Riga 1067, Latvia \\ ${ }^{2}$ Children Clinical University Hospital, Medical Genetics Clinic, Riga 1004, Latvia \\ ${ }^{3}$ Pauls Stradins Clinical University Hospital, Riga 1002, Latvia \\ ${ }^{4}$ Children Clinical University Hospital, Neurology Clinic, Riga 1004, Latvia
}

Correspondence should be addressed to Baiba Lace; baiba.lace@gmail.com

Received 28 May 2013; Accepted 18 July 2013

Academic Editors: D. B. Fee, F. C. Henderson, and J. C. Kattah

Copyright (C) 2013 Baiba Lace et al. This is an open access article distributed under the Creative Commons Attribution License, which permits unrestricted use, distribution, and reproduction in any medium, provided the original work is properly cited.

\begin{abstract}
Limb-girdle muscular dystrophies (LGMDs) is a heterogeneous group of muscular dystrophies that mostly affect the pelvic and shoulder girdle muscle groups. We report here a case of neuromuscular disease associated with Dupuytren's contracture, which has never been described before as cosegregating with an autosomal dominant type of inheritance. Dupuytren's contracture is a common disease, especially in Northern Europe. Comorbid conditions associated with Dupuytren's contracture are repetitive trauma to the hands, diabetes, and seizures, but it has never before been associated with neuromuscular disease. We hypothesize that patients may harbor mutations in genes with functions related to neuromuscular disease and Dupuytren's contracture development.
\end{abstract}

\section{Introduction}

Limb-girdle muscular dystrophies (LGMDs) is a heterogeneous group of muscular dystrophies that mostly affect the pelvic and shoulder-girdle muscle groups. LGMD is rare with an overall incidence of 1 per 100000 people [1]. LGMD is classified into two main groups: autosomal dominant (LGMD type 1 ) and autosomal recessive (LGMD type 2 ). The more common type is autosomal recessive with 16 genes or chromosomal loci identified to date [2-4]. The rarer form is autosomal dominant. Ten percent of all cases of LGMD belong to this group. So far, eight genes or chromosomal loci have been associated with the autosomal dominant form [57].

Diagnosis of the different types of LGMD is a challenging process due to the many genes involved, unidentified genes at known chromosomal loci, and the lack of common mutations in noninbred populations.

We report here a case of neuromuscular disease and Dupuytren's contracture, which has never been described before.
Dupuytren's contracture appears initially as a nodule containing highly contractile myofibroblasts. The myofibroblasts gradually develop into the cord, which leads to progressive fibrosis of the palmar fascia [8]. Myosin light chain activation is the result of a series of events, triggered by fibroblast and myofibroblast migration and contraction [9].

Dupuytren's contracture is a common disease. It is present in $4 \%$ of North European descendants [10]. Comorbid conditions with Dupuytren's contracture are a history of smoking, repetitive trauma to the hands, diabetes, and seizures [11].

\section{Case Report}

The patients were two brothers from a large family with multiple affected family members. See Figure 1.

III-2 Proband was a 62-year-old male, who complained of proximal muscle progressive weakness since the age of 50 .

Proximal muscle weakness, with distal leg, and bilateral ankle dorsiflexor muscle weakness, and atrophy on physical examination were observed. Gowers symptom was positive. 


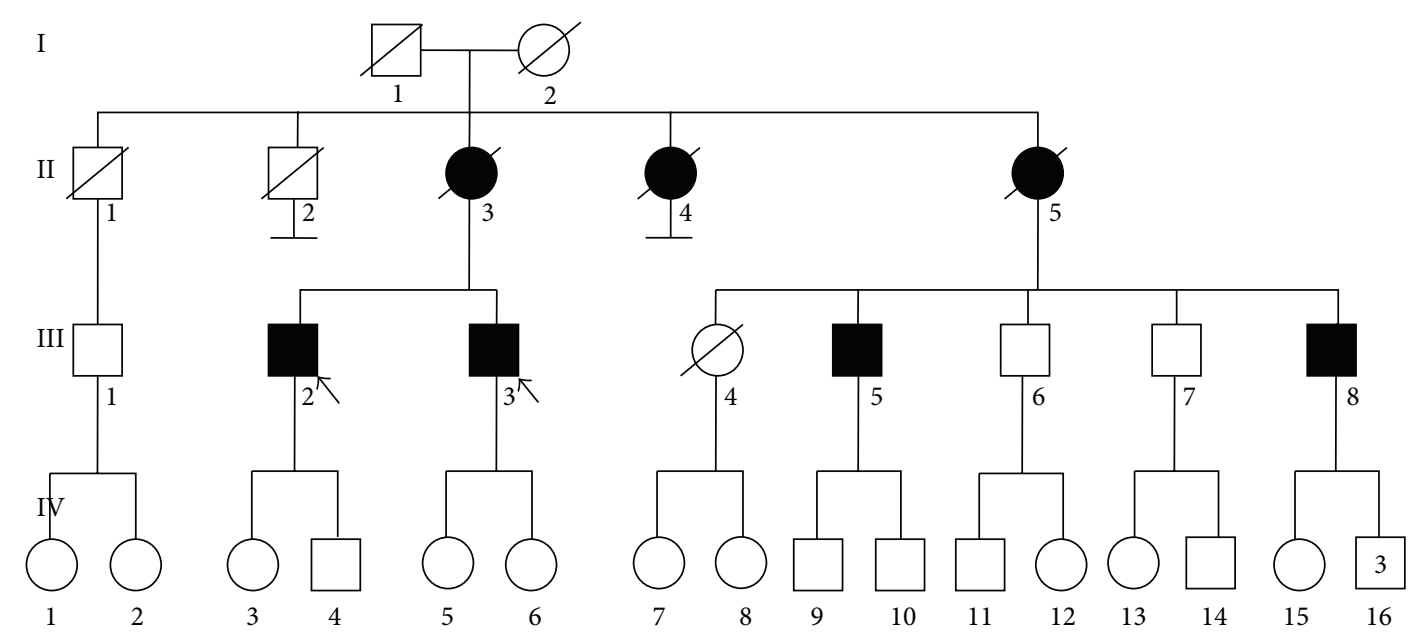

FIGURE 1: Family tree, black arrows indicate probands.

Neck flexor muscles showed mild weakness, but the facial muscles were normal. Dupuytren's contracture was in a palm.

Creatine kinase (CK) was mildly elevated at $527 \mathrm{IU} / \mathrm{L}$. Electromyography revealed two processes concomitantly, chronic lumbosacral radiculopathy level L5-S1 and myopathic disease. Magnetic resonance imaging of the spine revealed lumbar degenerative disk disease and L4 vertebral retrolisthesis. Electrocardiography showed left ventricular hypertrophy. Limb-girdle muscle dystrophy (LGMD) was diagnosed.

III-3 Proband was a 60-year-old male. His first complaints were muscle pain and gait disturbances, which started twelve years ago. He could not walk on his heels and after slow progression of the disease, he observed difficulties with climbing stairs.

Physical examination revealed shoulder-girdle muscle hypertrophy. Neck flexor muscles showed a mild weakness, but the facial muscles were normal. Scapular winging, proximal muscle weakness, with distal leg and bilateral ankle dorsiflexor muscle weakness and atrophy on physical examination were observed. Dupuytren's contractures were bilateral. See Figure 2.

All information about family members was obtained from the probands. Documentation about diagnosis was not available.

II-3 Person had proximal muscle weakness, which was more pronounced in the legs. He died at 92 years of age after a long period of immobility due to a hip fracture.

II-4 Person had proximal muscle weakness. He lost ambulation after twenty years.

II-5 Person was severely affected with muscle weakness. He lost ambulation at the age of 70.

III-5 Cousin had myopathy, proximal muscle weakness, and spinal deformity. He lost unaided walking at the age of 70.

III-8 Cousin had myopathy and proximal muscle weakness, but he is still ambulatory.

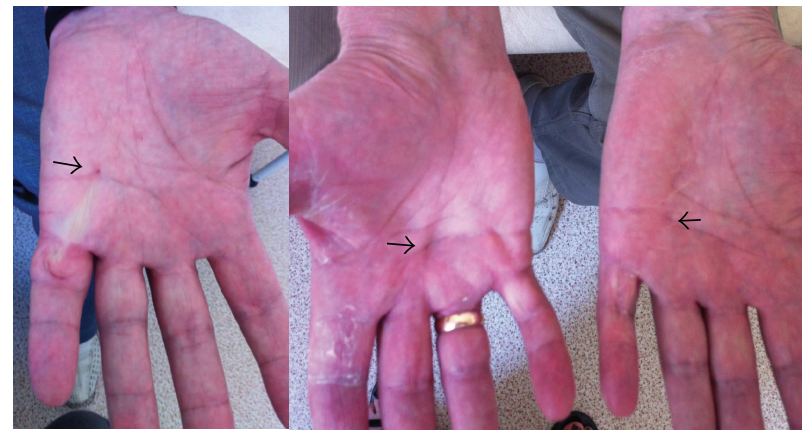

Figure 2: Hands of Probands III-2 and III-3. Arrows indicate contracture site. Distal muscle atrophy of hands.

IV-3 Girl of 31 years of age, who had mild scapular winging and initial Dupuytren's contracture (or node) of the right palm.

\section{DNA Diagnostics}

Sequencing of the CAV3 gene did not identify sequence variations in any of the analyzed family members (III-2, III-3, and IV-3). The most common mutations in the LMNA gene (1072G > A (Glu358Lys), 1357C > T (Arg453Trp) and 1718C > $\mathrm{T}$ (Ser573Leu)) were not observed.

\section{Discussion}

The risk of recurrence of Dupuytren's contracture recurrence for siblings is high (lambda ratio -2.9), indicating a strong genetic component, but it is a genetically heterogeneous disease. There have been familial reports about a mitochondrial and autosomal dominant type of inheritance [12]. Large families from Sweden showed isolated Dupuytren's contracture phenotype following autosomal dominant type of inheritance. Genome wide scan confirmed the highest LOD 
score in this family at chromosome 16q, but the gene was not identified [13].

Molecular analysis employing large association studies and functional analysis have been performed. The results indicated that several pathways (Wnt, TGF $\beta$, Akt, Integrin, etc.) are involved in the pathogenesis of this disease. Also, the impairment of numerous genes and their functions underlies the development of Dupuytren's contracture; for instance, several collagen types and myosin (MYH8) [14] are dysregulated. We hypothesize that patients from this family may harbor mutations in genes with functions related to neuromuscular disease and Dupuytren's contracture development. To the best of our knowledge this is the first report of cosegregation of Dupuytren's contracture and neuromuscular disease. However, we could not exclude Dupuytren's contracture as an incidental finding in the family, but affected patients do not have any of the risk factors for the development of Dupuytren's contracture.

\section{Acknowledgment}

Diagnostics were available due to ERDF funds no. 2010/0223/ 2DP/2.1.1.1.0/10/APIA/VIAA/025 New tests for the diagnosis of inherited neuromuscular diseases.

\section{References}

[1] J. R. W. Yates and A. E. H. Emery, "A population study of adult onset limb-girdle muscular dystrophy," Journal of Medical Genetics, vol. 22, no. 4, pp. 250-257, 1985.

[2] X. Q. Rosales, S. J. Moser, T. Tran et al., "Cardiovascular magnetic resonance of cardiomyopathy in limb girdle muscular dystrophy 2B and 2I," Journal of Cardiovascular Magnetic Resonance, vol. 13, no. 1, article 39, 2011.

[3] D. Hicks, A. Sarkozy, N. Muelas et al., "A founder mutation in Anoctamin 5 is a major cause of limb-girdle muscular dystrophy," Brain, vol. 134, no. 1, pp. 171-182, 2011.

[4] H. Gundesli, B. Talim, P. Korkusuz et al., "Mutation in exon If of PLEC, leading to disruption of plectin isoform if, causes autosomal-recessive limb-girdle muscular dystrophy," American Journal of Human Genetics, vol. 87, no. 6, pp. 834-841, 2010.

[5] S. H. Laval and K. M. D. Bushby, "Limb-girdle muscular dystrophies-from genetics to molecular pathology," $\mathrm{Neu}$ ropathology and Applied Neurobiology, vol. 30, no. 2, pp. 91-105, 2004.

[6] S. A. Greenberg, M. Salajegheh, D. P. Judge et al., "Etiology of limb girdle muscular dystrophy 1D/1E determined by laser capture microdissection proteomics," Annals of Neurology, vol. 71, no. 1, pp. 141-145, 2012.

[7] M. B. Harms, R. B. Sommerville, P. Allred et al., "Exome sequencing reveals DNAJB6 mutations in dominantlyinherited myopathy," Annals of Neurology, vol. 71, no. 3, pp. 407-416, 2012.

[8] G. M. Rayan and J. J. Tomasek, "Generation of contractile force by cultured Dupuytren's Disease and normal palmar fibroblasts," Tissue and Cell, vol. 26, no. 5, pp. 747-756, 1994.

[9] K. E. Kamm and J. T. Stull, "Dedicated Myosin Light Chain Kinases with Diverse Cellular Functions," Journal of Biological Chemistry, vol. 276, no. 7, pp. 4527-4530, 2001.
[10] S. Hindocha, D. A. McGrouther, and A. Bayat, "Epidemiological evaluation of dupuytren's disease incidence and prevalence rates in relation to etiology," Hand, vol. 4, no. 3, pp. 256-269, 2009.

[11] D. C. Ross, "Epidemiology of Dupuytren's disease," Hand Clinics, vol. 15, no. 1, pp. 53-62, 1999.

[12] L. Michou, J.-L. Lermusiaux, J.-P. Teyssedou, T. Bardin, J. Beaudreuil, and E. Petit-Teixeira, "Genetics of Dupuytren's disease," Joint Bone Spine, vol. 79, no. 1, pp. 7-12, 2012.

[13] F. Z. Hu, A. Nystrom, A. Ahmed et al., "Mapping of an autosomal dominant gene for Dupuytren's contracture to chromosome $16 q$ in a Swedish family," Clinical Genetics, vol. 68, no. 5, pp. 424429, 2005.

[14] B. Shih, S. Watson, and A. Bayat, "Whole genome and global expression profiling of Dupuytren's disease: systematic review of current findings and future perspectives," Annals of the Rheumatic Diseases, vol. 71, no. 9, pp. 1440-1447, 2012. 


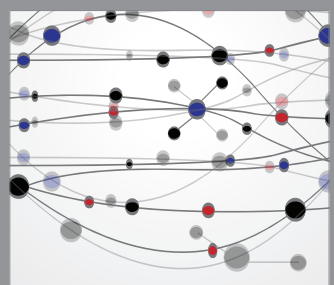

The Scientific World Journal
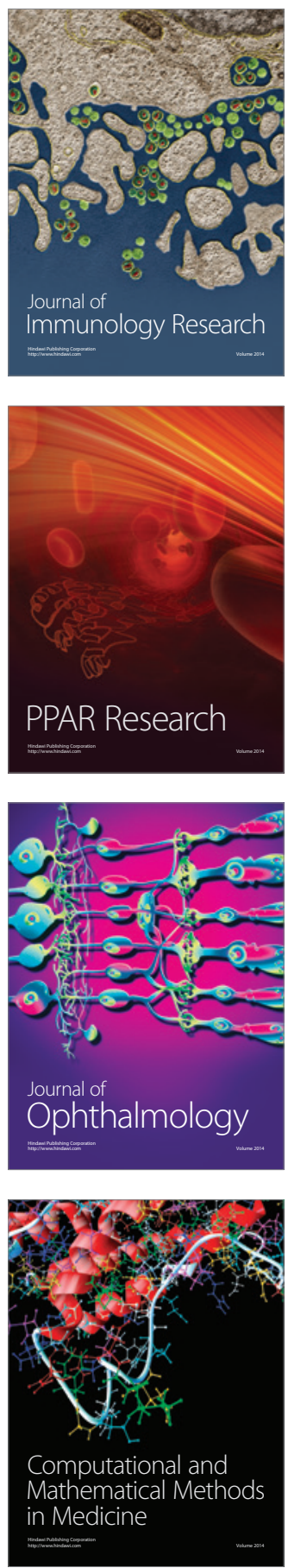

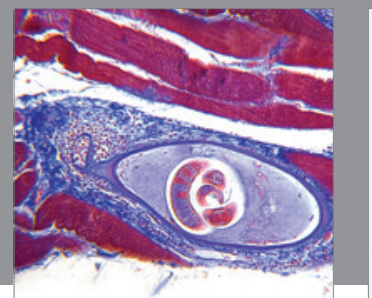

Gastroenterology

Research and Practice
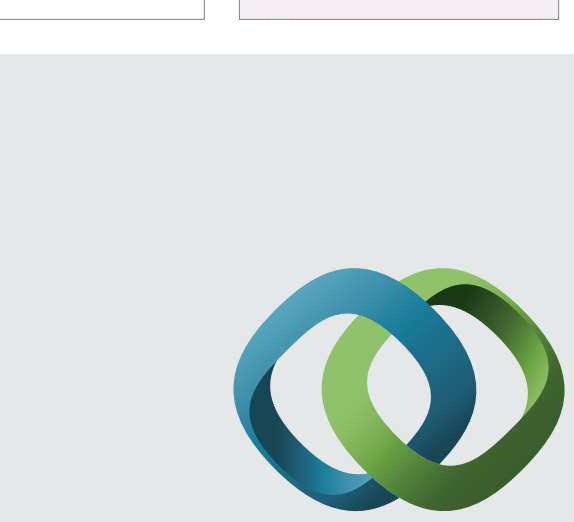

\section{Hindawi}

Submit your manuscripts at

http://www.hindawi.com
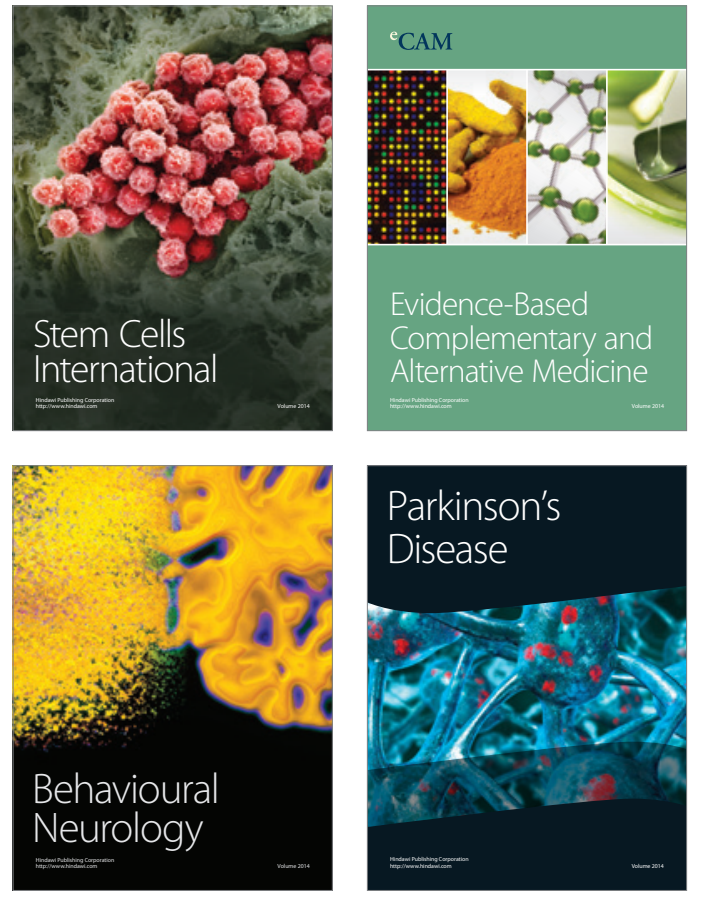
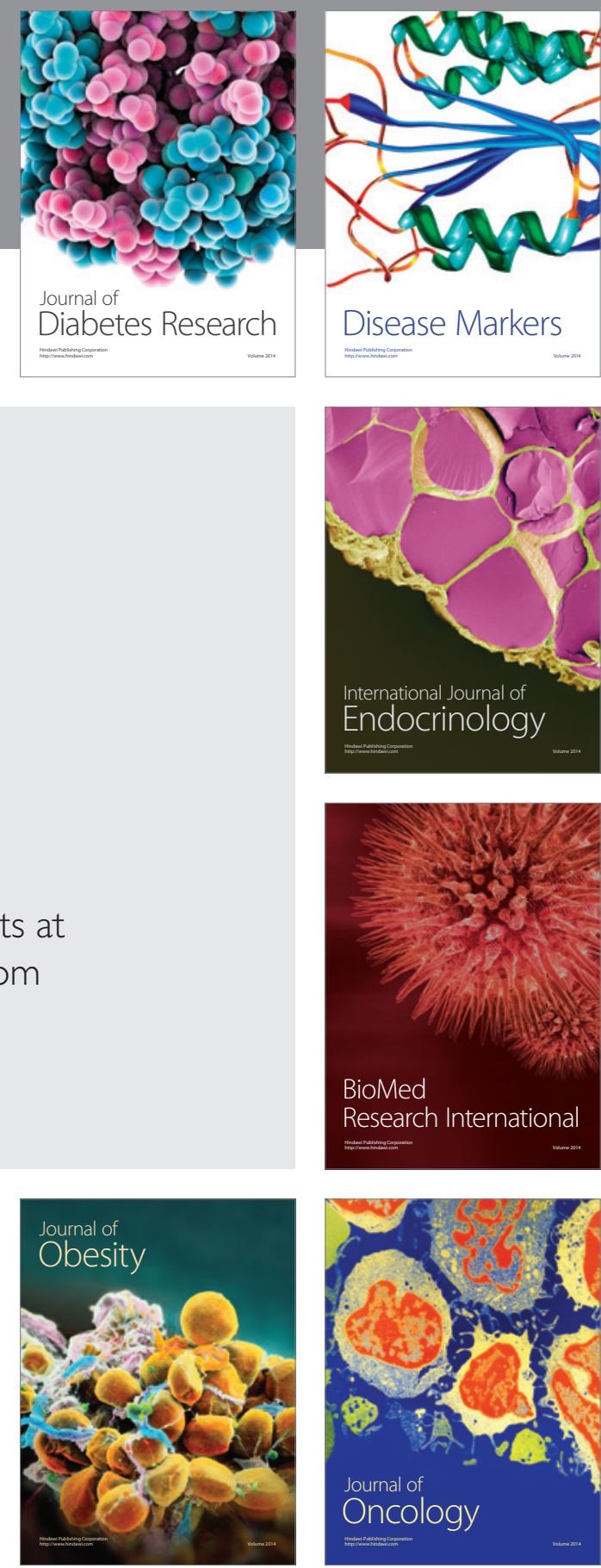

Disease Markers
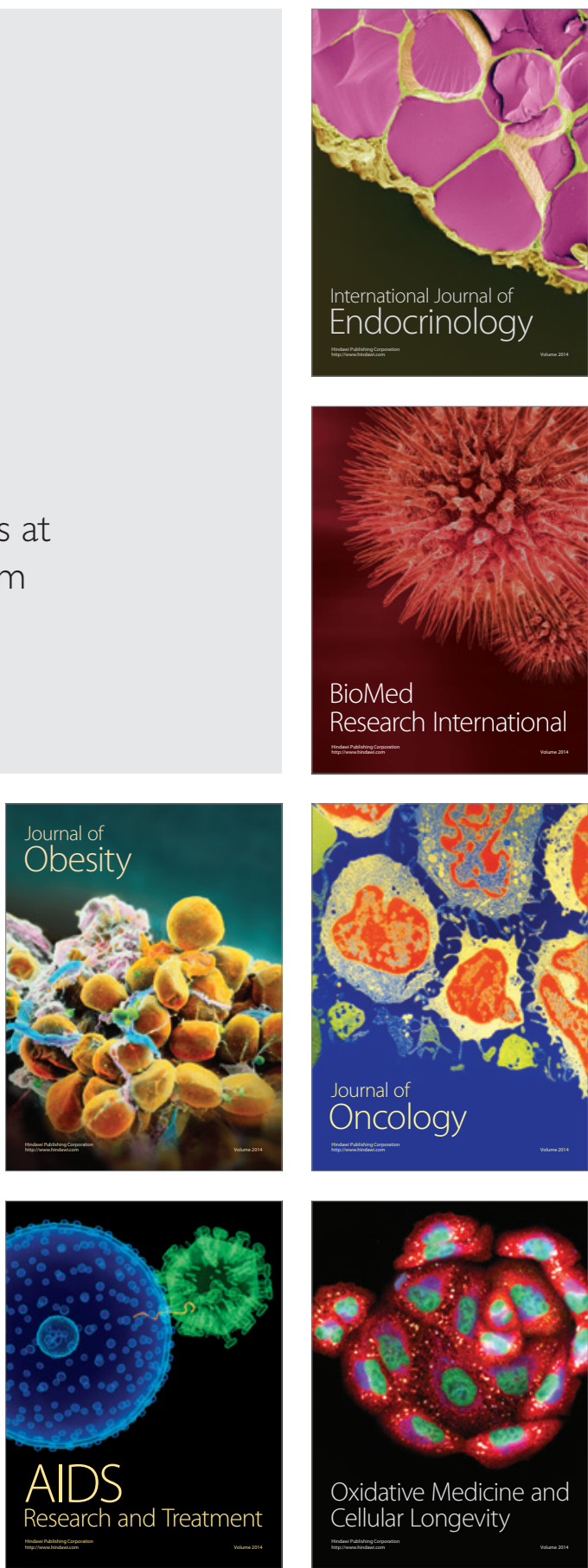